\title{
Chemical Characterization and Tribological Behavior of Kitchen Chimney Dump Lard (KCDL) as a Bio-lubricant
}

\author{
Suman Dey*, Madhujit Deb, Pankaj Kumar Das \\ Department of Mechanical Engineering, National Institute of Technology Agartala, 799046, India
}

Corresponding Author Email: suman2013mech@gmail.com

https://doi.org/10.18280/rcma.290303

Received: 2 March 2019

Accepted: 28 May 2019

\section{Keywords:}

bio-lubrican, fatty acid ester, IR spectrum,

tribotester, wear rate, $\mathrm{COF}$

\begin{abstract}
Immense study of environment friendly and renewable lubricant is now a day's major field of research for the overall sustainable development. Most of the challenges are taken towards recyclable waste to product. The Present work investigates the characterization and frictionwear behavior of Inconel 800 against 100Cr Steel applying Kitchen Chimney Dump Lard (KCDL) as a bio-lubricant. The characterization study by FTIR (Fourier Transform Infrared Spectroscopy) has shown the presence of fatty acid ester in KCDL. Tribological tests have been performed on Inconel 800 at different load and speed in a lubricated condition. From the experiment, it has been investigated that there is no such change in specific wear rate due to better lubricity property and the presence of strong bonded beneficial tribofilm on KCDL. The coefficient of friction (COF) increases with the increase in speed and load but it is less compared to waste cooking oil, and Castrol GTX 20W-50.
\end{abstract}

\section{INTRODUCTION}

Tribology is a subject of science and engineering that deals to interact between surfaces which have been showing great challenges for the scientists and industrialists. The reduction of wear and friction can help to reduce energy loss. To mitigate the energy loss due to wear and friction, various studies have been carried out by using different lubricant. Among all lubricants used, vegetable based bio lubricants have shown more advantage for their biodegradability, renewability and excellent lubrication performance. Due to the better lubricity, wear protection quality with excellent tribological behavior of plant based biodegradable oil helps industrialist to choose it as an environmental friendly lubricant. Better physico-chemical properties, high viscosity index and high flash point offered bio-lubricant a great alternative to reduce wear and heat from matting surfaces [1-3]. Because of limitation to use edible based bio-lubricant from vegetable oils (sunflower, coconut, soybean etc.), waste cooking oil (WCO) collected from food production industries, restaurants and kitchen can be used as an alternative [4]. It has been found that triglyceride structure of vegetable oils provide quality which is desirable in a lubricant. Experimentally it has been observed that long, polar fatty acid chain provides high strength lubricant films that interact strongly with metallic surfaces, which can helps to reduce both friction and wear [5]. The triacylglycerol structure with long fatty acid chain and presence of polar groups (like carboxylic acids and esters) in palm oil and rocket seed oil have shown almost similar spectra in Fourier transform infrared spectroscopy (FTIR) in the mid infrared region [6-7]. Different FTIR studies have been conducted by oils used in fried foods, animal fat or several bio-oil which gave similar types of absorbance at specific wavenumber/cm-1. Among which most of the mono-alkyl ester based bio-oil has an absorbance peak near $1700-1750 \mathrm{~cm}-1$ that indicates the presence of $\mathrm{C}=\mathrm{O}$ stretching vibration of the methyl ester [8-9].
An experimental investigation of waste vegetable oil (WVO) contaminated lubricants with amine phosphate as anti-wear additive reduce more wear and friction compared to an additive added normal lubricant. Contrary to that, waste palm oil with amine phosphate could be an alternative resource as a lubricant [10]. Using sesame and nigella sativa oils as lubricant gives better COF compared to saline water while studying tribological behavior of M30NW stainless steel against UHMWPE. Compared to the dry test, nigella sativa oil and sesame oil have shown reduced wear of $46 \%$ and $54 \%$ respectively. Because of high carbon contents in these oils it is advantageous for boundary lubrication which helps to form multi-molecular layer to reduce friction and wear [11]. The coefficient of friction and wear rate of Inconel 600 disk sliding against AISI 52100 pin lubricated with MO (mineral oil), AM101 (quaternary ammonium chloride), L-108 (1-methyl-3octylimidazolium tetrafluoroborate) and L-P106 (1-methyl-3hexylimidazolium hexafluorophosphate) at room temperature have shown that the operation of quaternary ammonium chloride is very similar to that of the mineral base oil. They are higher in air as compared to water during sliding Inconel 690TT against AISI 304. It has also been found that friction and wear volume is minimal with room temperature water as compared to water at $50{ }^{\circ} \mathrm{C}$ and $80{ }^{\circ} \mathrm{C}$. As the temperature increased, the wear amount increased because of the increase of the micro-pitting wear [12]. The tribological behavior of AISI 1045 steel on tri pin-on-disk reduced $91.5 \%, 57 \%, 53 \%$ and $23 \%$ wear for rapeseed oil, diesel contaminated biolubricant, biodiesel contaminated lube oil and used synthetic oil respectively as compared to diesel contaminated commercial synthetic lubricant (SAE 20W40). This clearly indicates that bio-lubricant and biodiesel reduced friction more effectively than diesel when contaminated with lube oil for particular loading and temperature conditions [13].

Wear is the undesirable progressive loss of material from the working surfaces as a result of their motion relative to one 
another. A number of studies have been performed over the last several decades to determine the wear loss in the parts which are in contact with each other. Wear leads to failure which may give rise to losses in terms of energy, material, economy and many other factors. Tribology helps in this matter by controlling energy losses due to friction, wear losses and oil consumption. The use of proper lubricant can helps the problem of wear failure in the machine parts. Waste cooking oil, natural fats and plant oil-based lubricants and derivatives have shown excellent lubricity and biodegradability, for which they have been investigated as a base stock for lubricants and functional fluids. All the problems related to wear and friction can be overcome by the application of KCDL as a lubricant base stock. In this paper, chemical characterizations of KCDL and tribological experiments have performed for Inconel 800 (nickel-chromium alloys) to investigate wear and friction at different load and speed applying Kitchen Chimney Dump Lard (KCDL) as a lubricant.

\section{EXPERIMENTAL METHODOLOGY}

\subsection{Materials}

The study has been carried by sliding test sample Inconel $800\left(20 \times 20 \times 5 \mathrm{~cm}^{3}\right)$ against $100 \mathrm{Cr}$ Steel $(10 \mathrm{~mm}$ diameter $)$. $100 \mathrm{Cr}$ Steel ball is used to investigate tribology test for Inconel 800 with the help of KCDL as a bio lubricant. The tensile strength of $100 \mathrm{Cr}$ steel and Inconel 800 is $650-880$ and 520 $670 \mathrm{MPa}$ respectively.

Table 1. Property of KCDL

\begin{tabular}{|c|c|c|c|c|c|c|c|}
\hline \multicolumn{2}{|c|}{$\begin{array}{c}\text { Density }\left(\mathrm{g} / \mathrm{cm}^{3}\right) \\
\rho\end{array}$} & \multicolumn{2}{|c|}{$\begin{array}{c}\text { Dynamic viscosity (centipoise) } \\
\mu\end{array}$} & \multicolumn{2}{|c|}{$\begin{array}{l}\text { Kinematic viscosity } \\
\text { (centistoke) }\end{array}$} & \multirow[t]{2}{*}{ Pour point } & \multirow[t]{2}{*}{ Viscosity index } \\
\hline \multicolumn{6}{|c|}{ Test method } & & \\
\hline \multicolumn{2}{|c|}{ Pycnometer } & $\begin{array}{l}\text { Rotat } \\
\text { (brook }\end{array}$ & $\begin{array}{l}\text { ometer } \\
\text { prime) }\end{array}$ & & & $\begin{array}{l}\text { Pour point } \\
\text { apparatus }\end{array}$ & \multirow[t]{3}{*}{402} \\
\hline $40^{\circ} \mathrm{C}$ & $100^{\circ} \mathrm{C}$ & $40^{\circ} \mathrm{C}$ & $100^{\circ} \mathrm{C}$ & $40^{\circ} \mathrm{C}$ & $100{ }^{\circ} \mathrm{C}$ & \multirow{2}{*}{$1.3^{\circ} \mathrm{C}$} & \\
\hline 0.982 & 0.946 & 180 & 65 & 183 & 68.75 & & \\
\hline
\end{tabular}

\subsection{Experimental setup}

\subsubsection{Fourier Transform Infrared (FT-IR) spectroscopy}

Fourier Transform Infrared (FT-IR) spectroscopy is a technique based on the vibrations of the atoms of a molecule. An infrared spectrum is commonly obtained by passing infrared radiation through a sample and determining what fraction of the incident radiation is absorbed at a particular energy. Infrared spectroscopy is a versatile experimental technique and it is relatively easy to obtain spectra from samples in solution or in the liquid, solid or gaseous states. Fourier transform spectrometer works in between $4000-0 \mathrm{~cm}$ ${ }^{1}$ of mid infrared region that uses not more than $0.5 \mathrm{ml}$ of sample to get the spectra. Sample crystal was cleaned with acetone-toluene-methanol based tri solvent mixture before the operation and the results were obtained on a computer system connected with the machine.

\subsubsection{Pin on disk tribotester}

The pin on disk Tribotester (model: TR-20LE) covers a laboratory procedure for determining the wear of material during sliding. Cross-section of the machine setup is shown in Figure 1. The range of friction force and normal force between which the machine works is 0 to 200 and 5 to $200 \mathrm{~N}$

\subsection{Collection and purification of KCDL}

The identification of suitable feedstock and subsequent biomass conversion would contribute significantly towards futuristic bio-energy utilities. The feedstock used for this study, KCDL has been collected easily from the kitchen chimney of restaurant. KCDL is primarily a kitchen waste (a bio-waste which is renewable in nature, since the primary feedstock is a vegetable oil) which can be collected during cleaning from the horizontal collecting duct present in a kitchen chimney without any expense. It is formed as a result of frying processes where the vapor of the cooking oil after condensation gets stored in liquid form in a chamber inside the collecting duct of a kitchen chimney. This type of oil can easily collect also from a household kitchen exhaust by the user at a certain day's interval. Before the characterization and triobology test, purification has been performed for KCDL to remove water vapor and dust particles. A $250 \mathrm{ml}$ of KCDL is mixed with $5 \mathrm{mg}$ of magnesium sulfate $\left(\mathrm{MgSO}_{4}\right)$ in a plastic bottle for about 7-8 hours for complete purification. The details about the property of KCDL are shown in Table 1. Viscosity is a common and most important property of a lubricant that directly influence equipment wear rate, energy consumption etc. As temperature rises viscosity of oil falls and vice versa. As a result to measure the quality of the oil it must also to have viscosity index. A high value of viscosity index has been observed for KCDL that exhibits less change in viscosity with temperature. respectively. Materials are tested in pairs under nominally non-abrasive conditions. In the pin-on-disk wear test, two specimens are required. One, a pin or ball that is positioned perpendicular to the other, usually a flat circular disk that rotates in between the speed range of 200 to $2000 \mathrm{rpm}$. The tester causes stationary pin/ball to press against the rotating disk at a known force and speed. In this present experiment instead of pin, a ball of $10 \mathrm{~mm}$ diameter has been fixed into the tester for the friction and wear test. The whole experiment is conducted at an average temperature of $25{ }^{\circ} \mathrm{C}$ and relative humidity of $60 \%$. During the test $\mathrm{COF}$ and specific wear rate are measured and reported.

\subsection{Friction and wear test}

Experiments are conducted on a disk of Inconel 800 with the help of $100 \mathrm{Cr}$ steel ball of $10 \mathrm{~mm}$ diameter under Kitchen chimney dump lard waste oil using a pin-on-disk Tribometer. Friction and wear test has been conducted with different wear track diameter like 10, 14, 18, $22 \mathrm{~mm}$ and sliding speed 250, 300 and $350 \mathrm{rpm}$ and for the loads 10, 20 and $30 \mathrm{~N}$. The specific wear rate $\left(\mathrm{mm}^{3} / \mathrm{N}-\mathrm{m}\right)$ and coefficient of friction for the distance of 300 meters are determined. 


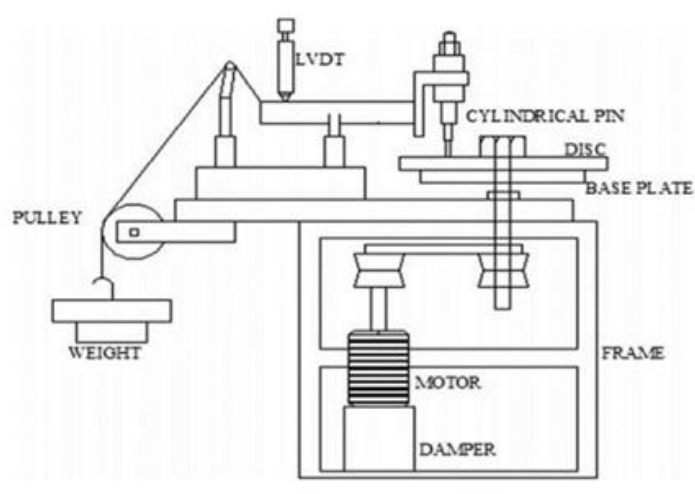

Figure 1. Cross section of a pin on disc tribometer [13]

\section{RESULTS AND DISCUSSION}

\subsection{FT-IR characterization}

Figure 2 shows oil characterization of KCDL and engine oil Castrol GTX 20W50 at different wavenumbers $\left(\mathrm{cm}^{-1}\right)$ from 0 to 4000 . In Table 2 spectral location $\left(\mathrm{cm}^{-1}\right)$ and absorbance band has been listed at specific absorbance peak. The region between $600-900 \mathrm{~cm}^{-1}$ indicate the presence of $=\mathrm{C}-\mathrm{H}$ functional groups that possess bending vibration at low energy frequency of the spectrum. At spectral location $722.03 \mathrm{~cm}^{-1}$ KCDL shows $\mathrm{C}-\mathrm{H}$ bending vibration on 0.646 absorbance level. The rocking mode of vibration $\mathrm{C}-\mathrm{H}$ bond at $722.03 \mathrm{~cm}$ ${ }^{1}$ [14] also helps to know about the presence of long chain fatty acid ester of KCDL. A strong absorbance peak at $1743.54 \mathrm{~cm}^{-}$ ${ }^{1}$ shows the presence of $\mathrm{C}=\mathrm{O}$ carbonyl group of a fatty acid ester. The absorbance band at 2853.00 and $2922.19 \mathrm{~cm}^{-1}$ indicate the presence of long chain hydrocarbons of alkane group [15] with $\mathrm{sp}^{3}$ hybrid. Symmetric and asymmetric stretching vibration of $\mathrm{C}-\mathrm{H}$ alkane group at 2853.00 and $2922.19 \mathrm{~cm}^{-1}$ is required high energy to cause vibration than that of $\mathrm{C}-\mathrm{H}$ alkene groups of bending vibration. The $\mathrm{sp}^{3}$ hybridized $\mathrm{C}-\mathrm{H}$ bonds in saturated hydrocarbons like octane absorb in the $2850-3000 \mathrm{~cm}^{-1}$ region. The bond strengths of carbon-hydrogen bonds are in the order of $\mathrm{sp}^{3}>\mathrm{sp}^{2}>\mathrm{sp}$ (hybridization). Because of the increased ' $\mathrm{s}$ ' character of the hybrid, it gives better overlap with the hydrogen s-orbital. From FT-IR spectrum of KCDL and Castrol GTX 20W50, it is cleared that spectrum formed in both oil have similar peaks at different wavenumbers with little change of absorbance limit except a peak at the range $1735-1750 \mathrm{~cm}^{-1}$.

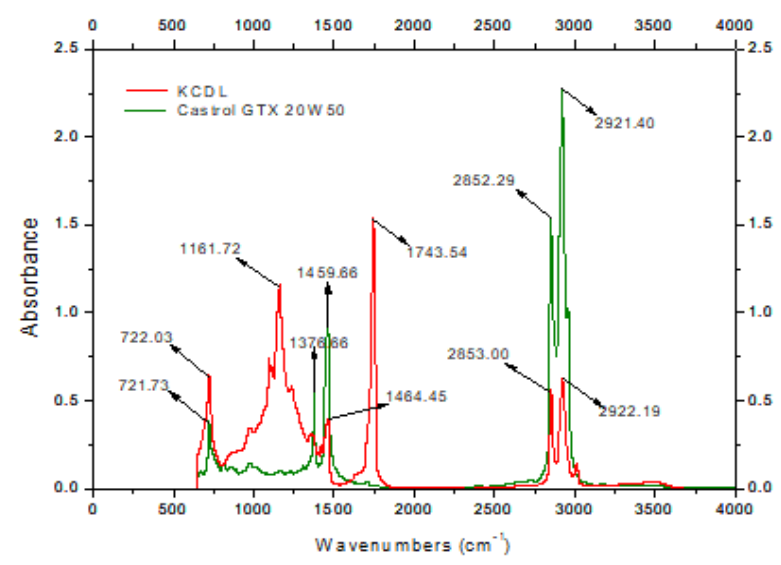

Figure 2. FT-IR spectra of KCDL and Castrol GTX 20W50

Table 2. Absorbance, wavenumbers, name of component for KCDL

\begin{tabular}{|c|c|c|c|}
\hline $\begin{array}{c}\text { Spectral } \\
\text { location } \\
\left(\mathbf{c m}^{-1}\right)\end{array}$ & $\begin{array}{l}\text { Absorba } \\
\text { nce }\end{array}$ & $\begin{array}{l}\text { Absorption } \\
\text { bands }\end{array}$ & $\operatorname{Range}\left(\mathrm{cm}^{-1}\right)$ \\
\hline 722.03 & 0.646 & $\mathrm{C}-\mathrm{H}$ & $600-900$ \\
\hline 1161.72 & 1.165 & $\mathrm{C}-\mathrm{O}$ bands & $1050-1150$ \\
\hline 1464.45 & 0.399 & $\mathrm{C}=\mathrm{O}$ deformation & $1450-1600$ \\
\hline 1743.54 & 1.536 & $\mathrm{C}=\mathrm{O}$ stretching & $1735-1750$ \\
\hline 2853.00 & 0.565 & $\begin{array}{l}\text { Symmetric } \mathrm{C}-\mathrm{H} \\
\text { vibration }\end{array}$ & $2850-3000$ \\
\hline 2922.19 & 0.627 & $\begin{array}{c}\text { Asymmetric C-H } \\
\text { vibration }\end{array}$ & $2850-3000$ \\
\hline
\end{tabular}

\subsection{Coefficient of Friction (COF)}

Figure 3(a) shows coefficient of friction at different sliding speed of 250, 300 and $350 \mathrm{rpm}$ at $10 \mathrm{~N}$ load. It has been found that $\mathrm{COF}$ increases as speed increases. The average $\mathrm{COF}$ measured for Inconel 800 is $0.03089,0.05266$ and 0.10329 at 250,300 and $350 \mathrm{rpm}$ respectively. The reason behind the increase in COF with increasing sliding speed is because of abrasive particles which formed during sliding because of breakdown of surface peaks. Coefficient of friction at different normal load 10, 20 and $30 \mathrm{~N}$ at $300 \mathrm{rpm}$ speed have been shown in Figure 3(b). It has also been observed that coefficient of friction increases as load increases. The average coefficient of friction measured for Inconel 800 is $0.05266,0.08072$ and 0.10945 for the load 10, 20 and $30 \mathrm{~N}$ respectively. In Figure 3 (c) it has been found that COF for dry condition at $300 \mathrm{rpm}$ speed and $10 \mathrm{~N}$ load is 0.6741 . Higher value of COF indicates that at dry environment Inconel 800 with $100 \mathrm{Cr}$ Steel is more prone to wear.
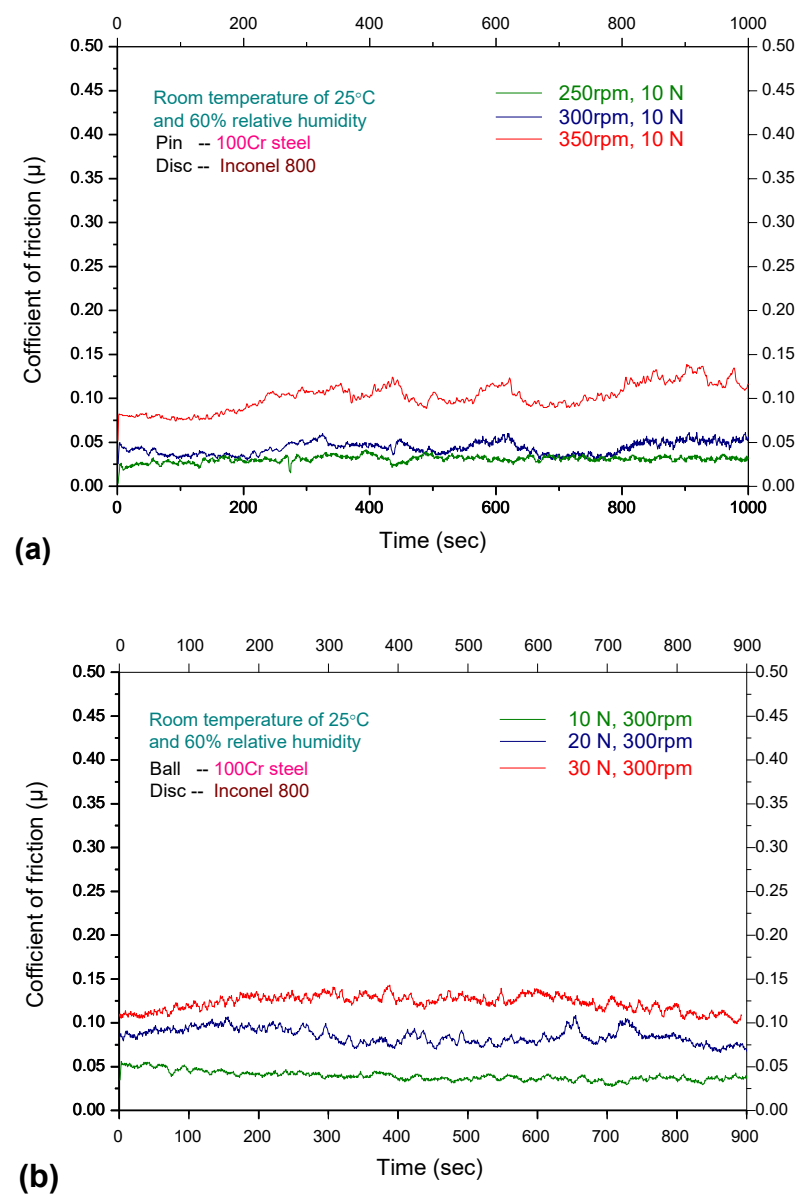

(b) 


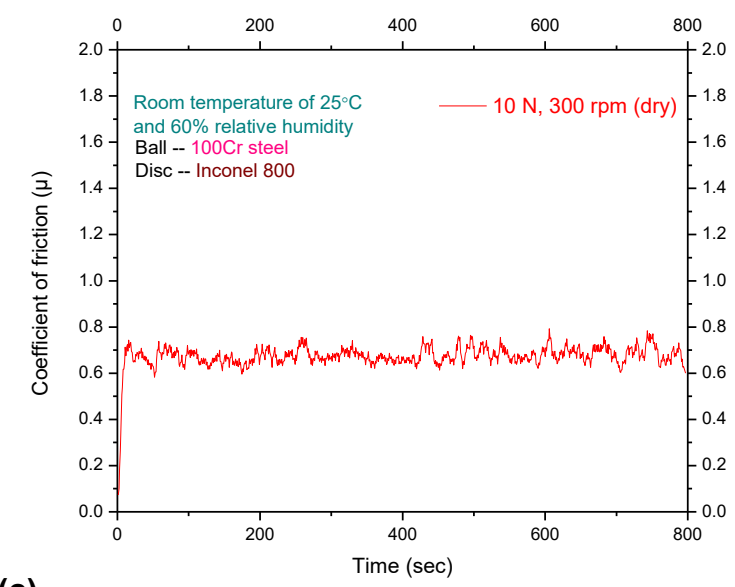

(c)

Figure 3. (a) COF at varying speed and constant load $10 \mathrm{~N}$;

(b) COF at varying load and constant speed $300 \mathrm{rpm}$; (c)

$\mathrm{COF}$ at $10 \mathrm{~N}$ load and $300 \mathrm{rpm}$ speed at dry condition

\subsection{Specific wear rate}

Figure 4(a, b) shows the specific wear rate at varying speed (at $10 \mathrm{~N}$ load) and varying load (at 300rpm) respectively for wet and dry condition. From the Figure 4 (a) it can be concluded that as speed changes there is no such change in specific wear with the application of KCDL. Whereas it is easy to explain that because of plastic flow of metal along the surface due to increase in load a little increase in specific wear rate has been found (in Figure 4 (b)). Specific wear rate and volume loss are calculated using following equations.

$$
\text { Specific wear rate }\left(\frac{\mathrm{mm}^{3}}{\mathrm{Nm}}\right)=\frac{\text { volume loss }\left(\mathrm{mm}^{3}\right)}{\operatorname{load}(\mathrm{N}) \times \text { sliding dist an ce }(\mathrm{m})}
$$

Volume loss $\left(\mathrm{mm}^{3}\right)=\pi \mathrm{D} \times$ Cross section area of wear track

$$
\begin{aligned}
& \text { Sliding velocity }\left(\frac{\mathrm{m}}{\mathrm{sec}}\right)=\frac{\pi \mathrm{DN}}{60,000} \\
& \text { Sliding distance }(\mathrm{m})=\frac{\pi \mathrm{DNT}}{60,000}
\end{aligned}
$$

where, $\pi=3.142$, $\mathrm{D}$ is diameter of the wear track in $\mathrm{mm}, \mathrm{N}$ is disc speed in rpm, $\mathrm{T}$ is time duration in second.

It is also been cleared from Figure 4(a,b) that specific wear rate at wet condition is much lower than that of dry condition. It can be explained that at high load the real surface area of contact increases, causing an increase in space connection due to which friction force and coefficient of friction increased [16]. Higher polarizability for the carbon atoms in the double bonded organic compound has high localized electron and charge density. The interaction between the metallic bodies due to presence of high-density charges is helpful for the formation of a strongly bonded beneficial tribo-film. In boundary lubrication, fatty acid oil migrated to the substrate where vacant sites are available. For the reason, high oxygen content of KCDL leads to an additional improvement in overall lubricity of the material [17]. Much faster wear progression has been found at the starting of operation. During this period asperities on the sliding surface are cut off and the contact area of sliding surface grows to an equilibrium size. As a result, after a certain period of time because of equilibrium condition of contact surface, wear becomes steady. It has been observed that at higher loads, the lubricating film thickness become thinner than some of the asperities present in the boundary lubrication regime. But the progression of wear has been controlled by long chain fatty acid and the esters in KCDL which acts as a surfactant [18].
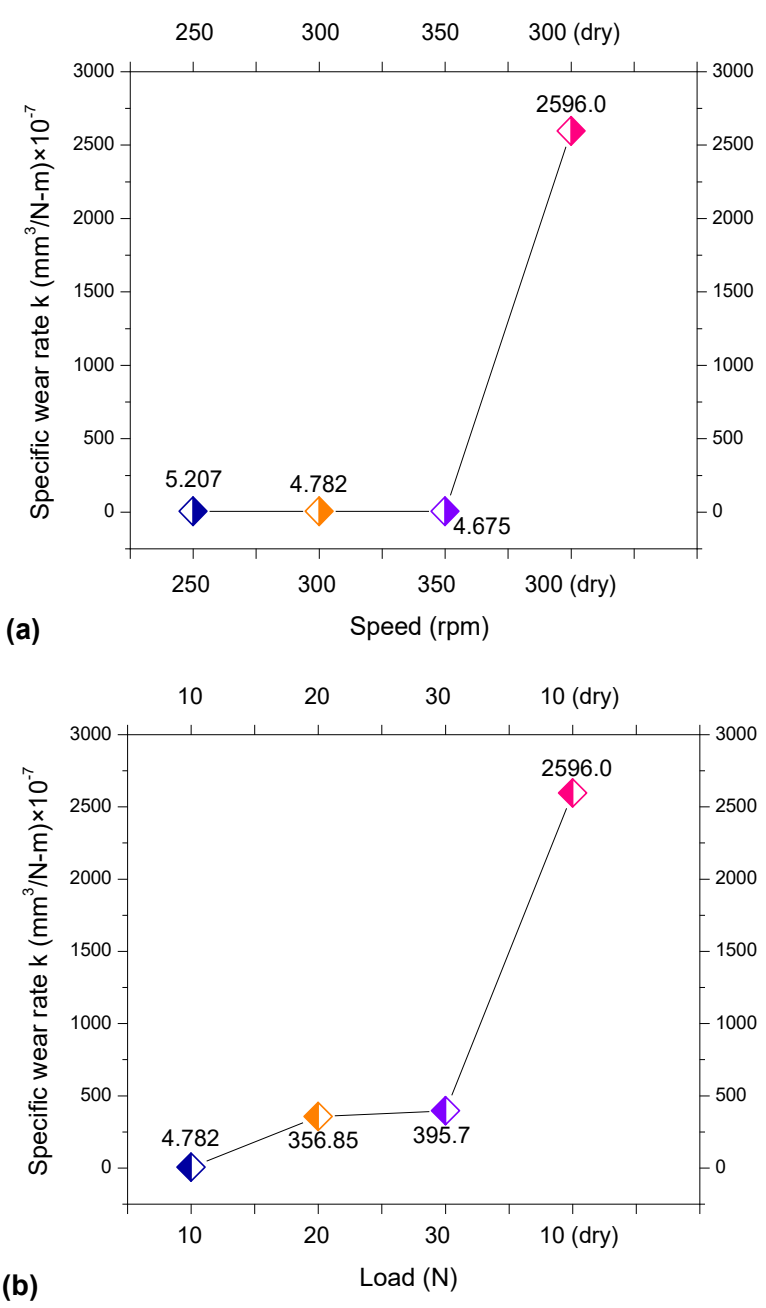

Figure 4. (a) Specific wear rate at varying speed and constant load (10 N); (b) Specific wear rate at varying load and constant speed (300 rpm)

\subsection{Comparison of KCDL with different engine oil}

Figure 5 shows the coefficient of friction for KCDL, waste cooking oil (WCO) and Castrol GTX 20W50. Coefficient of friction found at an average of $0.085,0.0610$ and 0.05266 for Castrol GTX 20W50, WCO and KCDL respectively. From the Figure 5 it is cleared that KCDL oil gives minimum values of coefficient of friction 0.05266 at $10 \mathrm{~N}$ load and 300rpm speed as compared to WCO and Castrol GTX 20W50. Based on the result obtained it is cleared from the Figure 5 that as compared to synthetic lubricant bio-degradable waste cooking and KCDL oil show minimum coefficient of friction. Low coefficient of friction of KCDL compared to Castrol GTX 20W50 and WCO is because of the presence of fatty acid compound and long hydrocarbon chain that gives better performance compared to other base lubricating oil. 


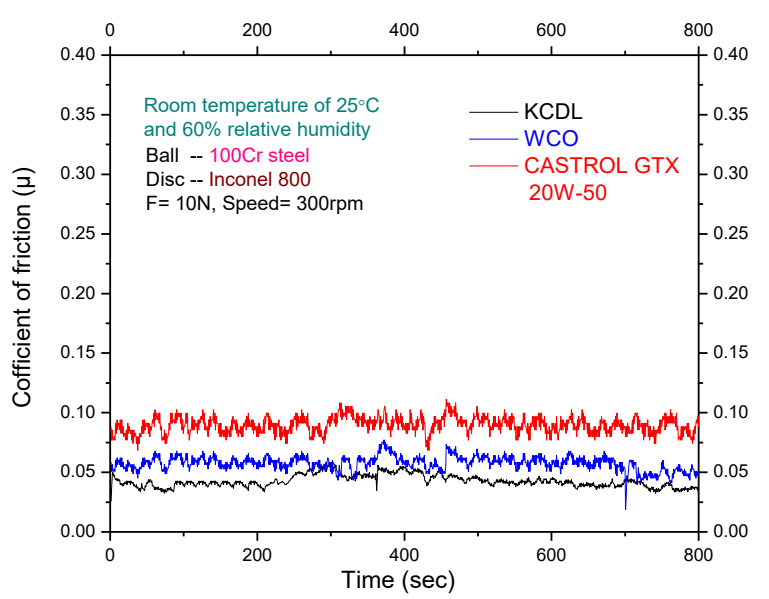

Figure 5. COF of different engine oil

\subsection{Surface image analysis}

Figures 6-8 show 3D profile images of Inconel 800 disk at different operating condition. From the close inspection from Figure 6(a), 6(b), 7(a), 7(b), 8(a) as load increases the worn surface shows the presence of deep longitudinal grooves that are parallel to wear direction. More metal transfer and pits which are an indication of little abrasive wear mainly attributed due to the absence of anti-wear additives in KCDL lubricant. Whereas there is no such change in surface morphology due to increasing speed. The maximum depth of penetration on changing speed is found very less as compared to changing load. Maximum depth of penetration at 250, 300 and $350 \mathrm{rpm}$ (at $10 \mathrm{~N}$ load) is found $0.344 \mu \mathrm{m}, 0.424 \mu \mathrm{m}$ and $0.428 \mu \mathrm{m}$ respectively. Whereas depth of penetration of 14.5 , 14.3 and $16.2 \mu \mathrm{m}$ is found for $20 \mathrm{~N}, 30 \mathrm{~N}$ and dry condition (at $300 \mathrm{rpm}$ ) respectively. From the Figure 8 (b), it is observed that more pits are formed due to pull out of material from surface at dry condition.
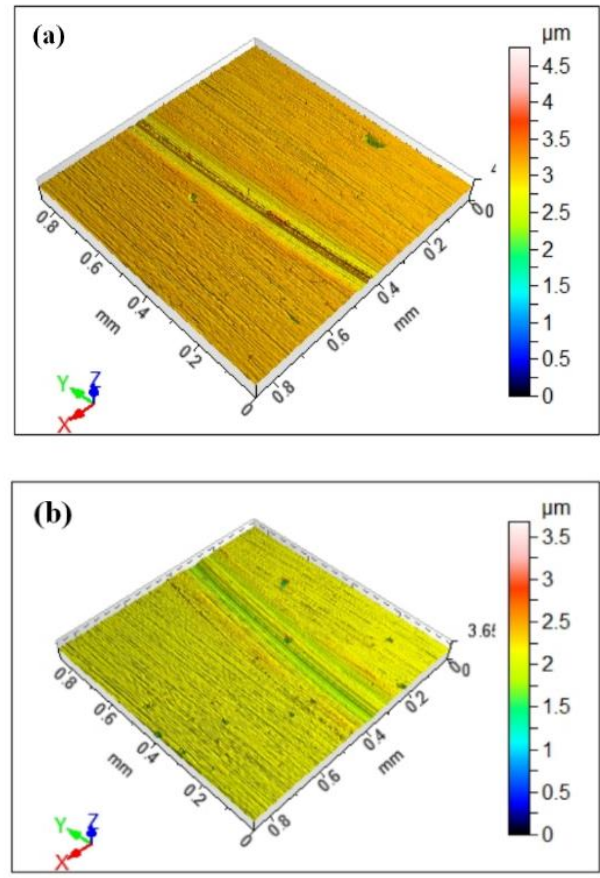

Figure 6. 3D profile image of Inconel 800 at (a) 250rpm and $10 \mathrm{~N}$, (b) 300rpm and $10 \mathrm{~N}$ using KCDL
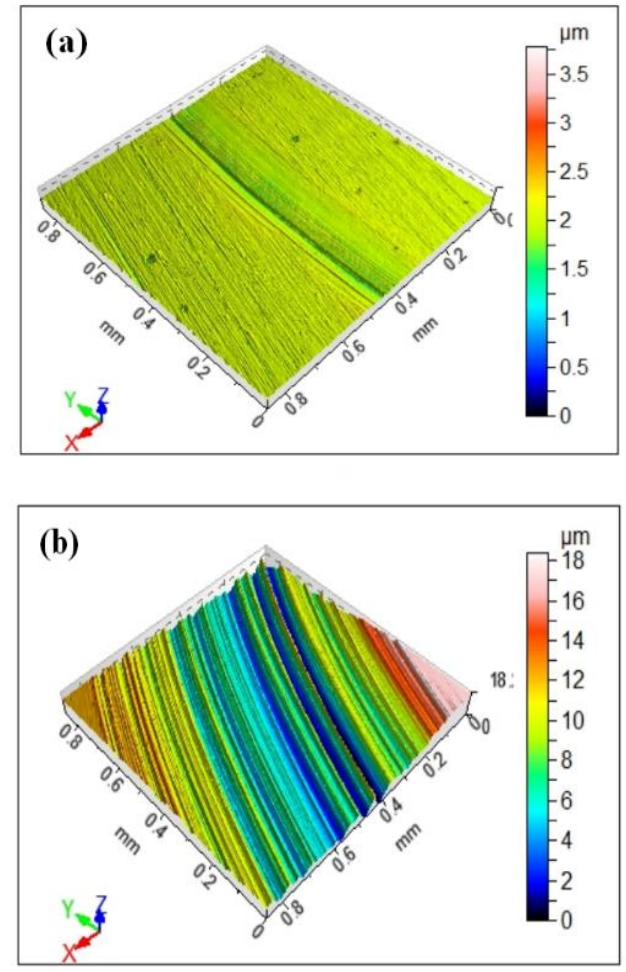

Figure 7. 3D profile image of Inconel 800 at (a) 350rpm and $10 \mathrm{~N}$, (b) $20 \mathrm{~N}$ and $300 \mathrm{rpm}$ using KCDL
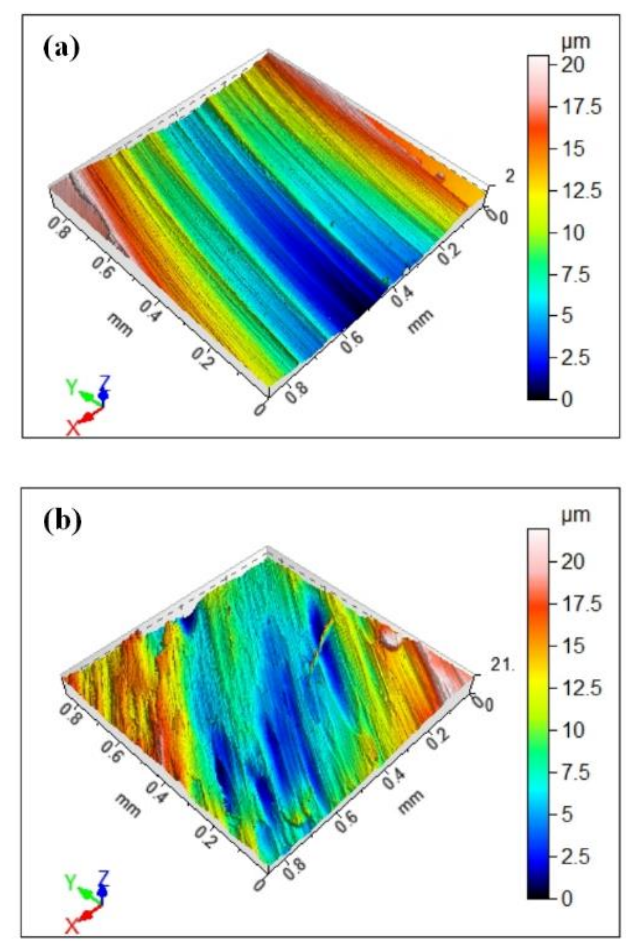

Figure 8. 3D profile image of Inconel 800 at (a) $30 \mathrm{~N}$ and $300 \mathrm{rpm}$ using KCDL, (b) $10 \mathrm{~N}$ and 300rpm without using KCDL (dry test)

\section{CONCLUSIONS}

In this study chemical characterization and tribology study has been performed for KCDL. Following are the important points have taken as conclusion from this work is as, 
$>$ Experimental study on FT-IR shows KCDL as a high free fatty acid ester of long carbon chain (C18:2) with two strong carbon-carbon double bonds.

$>$ FT-IR spectra of KCDL shows almost $80 \%$ similar trends of Linoleic acid methyl ester (unsaturated fatty acid).

$>$ At constant load and increasing sliding speed, coefficient of friction increases and specific wear rate decreases $8.16 \%$ and $2.23 \%$ respectively for every 50rpm increase in speed under lubricated condition.

$>$ At constant speed and increasing load both coefficient of friction and specific wear rate increases. As load increases from $20 \mathrm{~N}$ to $30 \mathrm{~N}$ specific wear rate increases $10.88 \%$.

$>$ The low values of specific wear rate are only because of the presence of triglyceride in KCDL which helps to form a thin tribo-layer in contact region.

$>$ There is no such change in specific wear rate with varying load and varying speed due to the tribo-film formation during the moving of contact surface with the help of KCDL.

\section{REFERENCES}

[1] Wagner, H., Luther, R., Mang, T. (2001). Lubricant base fluids based on renewable raw materials their catalytic manufacture and modification. Applied Catalysis A: General, 221(1-2): 429-442. https://doi.org/10.1016/S0926-860X(01)00891-2

[2] Salimon, J., Salih, N., Yousif, E. (2010). Biolubricants: Raw materials, chemical modifications and environmental benefits. European Journal of Lipid Science and Technology, 112(5): 519-530. https://doi.org/10.1002/ejlt.200900205

[3] Mobarak, H.M., Mohamad, E.N., Masjuki, N.H., Kalam, M.A., Al Mahmud, K.A.H., Habibullah, M., Ashraful, A.M. (2014). The prospects of bio-lubricants as alternatives in automotive applications. Renewable and Sustainable Energy Reviews, 33: 34-43. https://doi.org/10.1016/j.rser.2014.01.062

[4] Alotaibi, J.G., Yousif, B.F. (2016). Biolubricants and the Potential of Waste Cooking Oil. J.P. Davim (ed.), Ecotribology, J.P. Davim (ed.), Ecotribology, Materials Forming, Machining and Tribology, pp. 125-143. https://doi.org/10.1007/978-3-319-24007-7_5

[5] Fox, N.J., Stachowiak, G.W. (2007). Vegetable oil-based lubricants-A review of oxidation. Tribology International, 40: 1035-1046. https://doi.org/10.1016/j.triboint.2006.10.001

[6] Liew, W., Hsien, Y. (2014). Utilization of vegetable oil as bio-lubricant and additive. Towards Green Lubrication in Machining, 7-17.

[7] Tariq, M., Ali, S., Ahamad, F., Ahmad, M., Zafar, M., Khalid, N., Khan, M.A. (2011). Identification, FT-IR, NMR (1H and 13C) and GC/MS studies of fatty acid methyl esters in biodiesel from rocket seed oil. Fuel Processing Technology, 92: 336-341. https://doi.org/10.1016/j.fuproc.2010.09.025

[8] Mothe, C.G., Cesar, B., Castro, S.D., Mothe, M.G. (2011). Characterization by TG/DTG/DSC and FTIR of frying and fish oil residues to obtain biodiesel. J Therm Anal Calorim, 106: 811-817.

[9] Jiang, X.X., Ellis, N., Zhong, Z.P. (2011). Fuel properties of bio-oil/bio-lubricant mixture characterized by TG, FTIR and 1H NMR. Korean J. Chem. Eng., 28: 133-137. https://doi.org/10.1007/s11814-010-0328-y

[10] Kalam, M.A., Masjuki, H.H., Varman, M., Liaquat, A.M. (2011). Friction and wear characteristics of waste vegetable oil contaminated lubricants. Int J Mech Mater Eng (IJMME), 3: 106-112.

[11] Guezmil, M., Bensalah, W., Mezlini, S. (2007). Effect of bio-lubrication on the tribological behaviour of UHMWPE against M30NW stainless steel. Tribiology International, 94: 550-559. https://doi.org/10.1016/j.triboint.2015.10.022

[12] Jeong, S.H., Cho, C.W., Lee, Y.Z. (2005). Friction and wear of Inconel 690 for steam generator tube in elevated temperature water under fretting condition. Tribology International, 38: 283-288. https://doi.org/10.1016/j.triboint.2004.08.012

[13] Arumugam, S., Sriram, G. (2012). Effect of bio-lubricant and biodiesel-contaminated lubricant on tribological behaviour of cylinder liner-piston ring combination. Tribology Transactions, 55: 438-445. https://doi.org/10.1080/10402004.2012.667517

[14] Saifuddin, N., Refal, H. (2014). Spectroscopic analysis of structural transformation in biodiesel degradation. Research Journal of Applied Sciences, Engineering and Technology, 8(9): 1149-1159. https://doi.org/10.19026/rjaset.8.1079

[15] Shuit, S.H., Lee, K.T., Kamaruddin, A.H., Yusup, Suzana. (2010). Reactive extraction of jatropha curcas L. seed for production of biodiesel: Process optimization study. Environ. Sci. Technol., 44(11): 4361-4367. https://doi.org/10.1021/es902608v

[16] Al-Samarai, R.A., Haftirman, Ahmad K.R., Al-Douri, Y. (2012). Effect of load and sliding speed on wear and friction of aluminium- silicon casting alloy. International Journal of Scientific and Research Publications, 2: 1-4.

[17] Arumugam, S., Sriram, G. (2014). Synthesis and characterisation of rapeseed oil bio- lubricant- its effect on wear and frictional behaviour of piston ring-cylinder liner combination. Journal of Engineering Tribology, 228: 1308-1318. https://doi.org/10.1177/1350650112458398

[18] Shahabuddin, M., Masjuki, H.H., Kalam, M.A., Bhuiya, M.M.K., Mehat, H. (2013). Comparative tribological investigation of bio-lubricant formulated from a nonedible oil source (Jatropha oil). Industrial Crops and Products, 47: 323-330. https://doi.org/10.1016/j.indcrop.2013.03.026

\section{ABBREVIATION}

$\begin{array}{ll}\text { KCDL } & \text { Kitchen chimney dump lard } \\ \text { FTIR } & \text { Fourier transform infra-red } \\ \text { COF } & \text { Coefficient of friction } \\ \text { WVO } & \text { Waste vegetable oil } \\ \text { SAE } & \text { Society of automotive engineers } \\ \text { AISI } & \text { American iron and steel institute }\end{array}$

